Delft University of Technology

\title{
Creating and managing knowledge in design by 'standing on the shoulders of giants'
}

Horvath, I.

DOI

10.3233/JID190021

Publication date

2020

Document Version

Accepted author manuscript

Published in

Journal of Integrated Design \& Process Science

\section{Citation (APA)}

Horvath, I. (2020). Creating and managing knowledge in design by 'standing on the shoulders of giants'. Journal of Integrated Design \& Process Science, 23(4), 1-4. https://doi.org/10.3233/JID190021

\section{Important note}

To cite this publication, please use the final published version (if applicable).

Please check the document version above.

\section{Copyright}

Other than for strictly personal use, it is not permitted to download, forward or distribute the text or part of it, without the consent of the author(s) and/or copyright holder(s), unless the work is under an open content license such as Creative Commons.

\section{Takedown policy}

Please contact us and provide details if you believe this document breaches copyrights.

We will remove access to the work immediately and investigate your claim. 


\section{Editorial:}

\section{Creating and managing knowledge in design by 'standing on the shoulders of giants'}

Those who have been involved in editing a regular or special issue of a journal know without saying that cohesion of the included articles typically amplifies the message and strengthens the impact of the contributions. I must confess that I was pondering for a rather long time about the question: What is common in the articles that have been chosen for publication in this regular issue? My first impression was that there was a similar methodological pattern in all four articles, but it was not obvious immediately. Once the well-known saying of Isaac Newton came to my mind. He said that science is about 'standing on the shoulders of giants'. That is, every new discovery builds upon the work that came before it, even if it contradicts and overturns that work. To understand the motivation and meaning behind the new ideas, it is first necessary to understand the essence of the old ideas. In other words, it means that we cannot simply jump in at the deep end without understanding why the field has taken the direction that it has. Having the quote in the mind proved to be very useful with regard to capturing the shared methodological pattern and the conceptual cohesion among these apparently very different articles. The fact of the matter is that each of them uses an already known, even consolidated scientific concept or phenomenon in new context. As it will be evidential after reading the articles, it is also common that, by doing so, they arrive at novel, proper and useful results.

In the case of the article included first, the already known scientific concept is the method of term frequency and correlation analysis, which was among others proposed by Hou, J.L., Yu, F.J. and Lin, R.K. in 2006, and which was used by the current authors to investigate the relationships among patents [1]. The second article reuses the concept of creative collaborative spaces, originally proposed by Eriksson, P.E. and Swenberg, T. in 2012, to capture and integrate three important aspects of the phenomenon of collaborative creativity [2]. The third article applied the widely accepted and used knowledge conversion mechanism, first proposed by Nonaka, I. and Takeuchi, H. in 1995, in knowledge creation and management in the context of costume design [3]. Lastly, the fourth article operationalized the idea of Galois lattice as the key concept for formal concept analysis based on Galois connection between sets of objects and sets of attributes, as discussed by Wille, R. in 1992 [4]. The references listed at the end of this Editorial may help readers understand the theoretical and methodological fundamentals of the concepts and phenomena underpinning the included papers.

Submitted by Qi Cao, Hengjin Cai, Jingjing Wang, Xiaoluo Ding, and Yi Yang, the first article is entitled: 'A scientometric study of technological trend based on patents'. The authors used term frequency analysis (TFA) to correlate keywords in the patent descriptions from 2005 until 2012. The frequency of the keywords reflects the hotspots in an application field, since they are related to emergence of new inventions or to appearance and proliferation of technologies in the concerned field. The authors assumed that the frequencies indirectly show the trend of technological development. For TFA, the keywords in the titles, abstracts and claims of the patent documents were selected and ordered. After counting the frequency of occurrences, the high-frequency keywords were refined and displayed as points in the system of coordinates. In the analysis, the points formed by the annual term frequency values were interconnected with polylines, and the graphs generated this way clearly showed the progression of highfrequency nouns, verbs, and adjectives. The results obtained by the authors from China and Australia revealed the in-process development of trends and the hotspots, and based on this information guidance can be provided for decision-making in a certain field. Specifically, the authors focused on the state of the art concerning organic materials and the related technologies, and prognosticated a substantial growth of using OLED. Based on this, they envisioned that the markets for it would continue to grow. Though essential to make sure that the results are reliable enough, dimension reduction and cluster analysis of 
claim would have been needed, but were not carried out in this study. This is recommended for followup studies.

The title of the second article is 'Agents, design and creativity in moving image postproduction: Conditions for collaborative creativity in digital media'. The Swedish authors, Thorbjörn Swenberg and Árni Sverrisson, analyzed how creativity is constrained in the making of films and TV programs as a consequence of the shift to digital production technology. They adapted the concept of creative collaborative spaces (CCS) in order to be able to describe these constraints, but also introduced the concept of audiovisual assemblies to facilitate collaboration analysis. The authors identified two contradicting practices: First, the development of new conventions reallocates the roles and the resources of making of audiovisual assemblies. Second, the high rate and broad range of incremental technological changes demand unconventional, creative problem-solving practices from everyone involved. Examples are provided from an innovative Swedish TV-production. The concept of CCS identifies three dimensions for consideration: (i) expressive potential (tool capacity and user's skill), (ii) time to spend on creative work, and (iii) digital information available for processing (quality of the material). The conducted analysis involved both the interconnectedness and the mutual dependencies of these three dimensions. The creative aspects were found in the choice of audiovisual expressions, how to achieve them, and how to handle the interplay between the different expressions. They were dependent on the several different craft-persons and associated with the various methods applied. This article presents the principles for analyzing the making of TV-programs and other similar audiovisual assemblies. The authors propose reconstruction of the workflows towards collaborative creativity and argue that the creative adaptation of sound and image features should be understood as a kind of collaborative audiovisual design work. In this way, all those involved in the post-production process can contribute to the overall design. The design workflow duality challenge of collaborative creativity is a relevant topic for further studies in several fields of design.

Entitled "Application of knowledge management in costume design: The case of Measure for Measure", the article of Yi-Meei Wang and Tung-Jung Sung, focuses on understanding and handling knowledge in this creative professional field and unique application of design. The authors from Taiwan claim that strategic application of knowledge management in costume design is still at early stage in Asia. Thus, their research question concerned how knowledge management techniques can be applied to costume design projects to regulate and integrate the complex work procedures. The concrete research work was based on the knowledge management loop (the so-called SECI model), first presented by Nonaka \& Takeuchi in the mid-1990s. The SECl model includes four knowledge conversion mechanisms, which concern: (i) tacit knowledge -> socialization $->$ tacit knowledge, (ii) explicit knowledge -> internalization $->$ tacit knowledge, (iii) tacit knowledge -> externalization -> explicit knowledge, and (iv) explicit knowledge - > combination $>$ explicit knowledge. To contribute to the progress in costume design, the authors completed a case study and content analysis to understand the process of knowledge accumulation. Using the case of the recent production of Shakespeare's Measure for Measure as an example, the authors analyzed the design knowledge created in different phases of costume design and derived a framework for knowledge management considering the modules of the costume design process. Though a lot of tacit (subjective and intangible) pieces of information and knowledge are involved in this process, the authors focused on the use of a design system database and digital calculations, but intrinsic issues and challenges of tacit knowledge management in the context of costume design need further elaboration. Due to limitations, only one case was analyzed. The authors argue that applying the theory of systematic knowledge management and the SECI model to costume design is a groundbreaking but feasible attempt in the world of theaters and the outcome of their work is significant from both theoretical and practical perspectives for the concerned field of design. They identified five advantages of application of knowledge 
management in the costume design process: (i) sustainability, (ii) consistency, (iii) convertibility, (iv) immediacy, and (v) shareability.

The last article is contributed by an American pair of authors, Jihoon Kim and Kyoung-Yun Kim, under the title 'Galois lattices-based formal design concept analysis for crowdsourcing design '. The work rests on the three pillars identified in the title. The Galois-lattice is a graphical method of representing knowledge structures. The abstract structure of G-lattice consists of a partially ordered set in which every two elements have a unique supremum (also called a least upper bound or join) and a unique infimum (also called a greatest lower bound or meet). The nodes of G-lattices represent all the possible concepts in a given body of knowledge in the sense that a notion defines a set of individuals or properties with no exceptions or idiosyncrasies. As a recent development, design has become supported by crowdsourcing. The vast knowledge created and contributed by crowds enhances a wide exploration and utilization of design ideas. However, (i) the limited amount of information called 'scarcity', (ii) non-guaranteed quality of contributions, and (iii) similar or contradicting contributions made by unspecified participant groups made it difficult to systematically analyze and reuse design concepts. This article presents a formal analysis method for design concepts generated by crowdsourcing design activities. To enable the formal design concept analysis, first a design feature taxonomy was developed by considering crowdsourcing design environment. In this taxonomy, various design features and participant evaluation features were constructed. The Galois lattice-based formal concept analysis was employed as a design concept analysis method. The pivot power case was used to show that the presented method was applicable to a practical crowdsourcing design environment. Finally, precision and recall tests were conducted through a focus group interview and the results from the design analysis without and with the participant evaluation were compared. As a scientific contribution, a formal design analysis method was introduced in this article to represent and extract concepts from crowdsourcing design activities. Since the proposed method can generate concepts from the sparse pieces of data or information, one of the major constraints of crowdsourcing design - namely, limited amount of information - can be eased. This research also showed that setting up a crowdsourcing design platform and applying participant information were useful in design concept generation and analysis.

As a token of appreciation, I would like to gratefully acknowledge the valuable contribution and excellent cooperation of the authors. I must also acknowledge my editor colleagues for their insightful and constructive comments concerning the draft version of this Editorial. I am now dispatching this regular issue to our readership in the hope that it not only provides useful information to many researchers working in similar fields, but also shows decent examples of how new knowledge can be created in various contexts based on 'standing on the shoulders of giants'.

Imre Horváth

editor

\section{References:}

[1] Hou, J. L., Yu, F. J., \& Lin, R. K. (2006). A knowledge component analysis model based on term frequency and correlation analysis. Journal of Computer Information Systems, 46(4), 64-77.

[2] Eriksson, P.E. \& Swenberg, T. (2012). Creative space in contemporary Swedish moving image production. Journal of Integrated Design and Process Science, 14(4), 55-72.

[3] Nonaka, I., \& Takeuchi, H. (1995). The knowledge-creating company: How Japanese companies create the dynamics of innovation. New York: Oxford University Press. 
[4] Wille, R. (1992). Concept lattices and conceptual knowledge systems. Computers and Mathematics with Applications, 23(6-9), 493-515. 